\title{
Mapping of the urban tree population in gardens of Ulhasnagar, District Thane, Maharashtra using Geographic information system (GIS)
}

\author{
Geetha Menon* \\ Department of Botany, R.K. Talreja College, Ulhasnagar, Thane - 421003 (Maharashtra), India \\ Shital Gharge \\ Department of Botany, R.K. Talreja College, Ulhasnagar, Thane - 421003 (Maharashtra), India \\ *Corresponding author. Email: drgeetamenon@gmail.com
}

\section{Article Info}

https://doi.org/10.31018/ jans.v13i3.2736

Received: Mau 27, 2021

Revised: August 3, 2021

Accepted: August 9, 2021

\section{How to Cite}

Menon, G. and Gharge, S. (2021). Mapping of the urban tree population in gardens of Ulhasnagar, District Thane, Maharashtra using Geographic information system (GIS). Journal of Applied and Natural Science, 13(3), 923 - 928. https:// doi.org/10.31018/jans.v13i3.2736

\begin{abstract}
Urban trees today are a crucial component that defines the healthy and liveable environment of a city. A city's database includes streets, building, footprints, overhead and underground utilities, workforce areas, pest/disease quarantine zones, parks, and pending development areas in addition to the tree database such as tree location, species, diameter at breast height $(\mathrm{DBH})$, and canopy width. The present study aimed at mapping the tree population of some selected gardens and parks in Ulhasnagar using Geographic Information Systems (GIS). GIS is an integrated system of computer hardware, software, data and trained personnel for analyzing and displaying all forms of geographically referenced information. GIS-based map shows the location for each tree species found in the selected 12 gardens of Ulhasnagar. Green colour represents dense green canopy represented by the above-ground biomass, and yellow represents moderate, while red indicates scarce or limited aboveground biomass. The green colour actually represents the volume of biomass and not the density or the number of trees and shows the concentration of carbon pools in the study area. Updating data in GIS is much more cost-efficient and less time consuming than having to redraw maps manually. Urban foresters and urban planners can work together using GIS for better management of this resource. This study is one of the pioneering footsteps towards appreciative resources and thus enabling the researchers in developing an appropriate management strategy. The data will help us to analyze and interpret better and eventually conceptualize the above-ground biomass in the entire area of gardens.
\end{abstract}

Keywords: Arc view, Breast height, Geographic Information System, Tree location

\section{INTRODUCTION}

Several opportunities come along with urbanization for the growth of economic, social, and technology sectors, offering advantages to society in terms of better living and healthcare facilities and employment opportunities. Nonetheless, some major drawbacks of urbanization are overcrowding and environmental degradation. In order to comprehend sustainable and environmentally friendly urbanization, there is a hurried need for comprehensive land use planning and of urban settlements by giving due consideration to create and sustain urban green spaces such as parks, gardens, roadside vegetation, etc. They play a key role in reducing air pollution, mitigating climate change, and providing various ecosystem services. However, these urban green spaces are being deteriorated substantially due to booming urbanization in developing countries such as India
(Ramaiah and Avtar, 2019). Most urban open spaces are green spaces but occasionally include other kinds of open areas too. The landscape of urban open spaces can range from playing fields to highly maintained environments to relatively natural landscapes (Jayashinge et al.,2018). Urban green spaces (UGS) are extremely decisive, particularly in developing countries where air pollution levels are extremely high. They play a vital role in purifying air, thus improving the air quality and serve as a valuable source for enabling urban agriculture, regulating the microclimate, and controlling the urban heat island phenomenon (Jennings et al., 2016). Furthermore, the UGS reduce soil erosion, noise pollution, and energy use by regulating the surface temperatures of urban canyons (Qian et al.,2015). Urban greening policies are important for revitalizing communities, reducing the financial burdens of healthcare and increasing quality of life. Most policies 
focus on community benefits and reduce negative effects of urban development, such as surface runoff and the urban heat island effect. Historically, access to green space has favoured wealthier and more privileged communities. Thus the recent focus in urban greening has increasingly focused on environmental justice concerns and community engagement in the greening process (Albro, 2020).

Ulhasnagar, the study site, is a fast-expanding urban city. Urban forests, due to their relatively low tree cover, typically store less carbon per hectare in trees than forest stands. Biomass is an important indicator in carbon sequestration; therefore, estimating the biomass in trees is the leading step in carbon counting. Forest biomass acts as an important indicator of carbon resources and carbon sequestration potential in terrestrial systems (Le Toan et al., 2011). Estimates of forest biomass enable direct measurement of carbon storage and provide initial values for process-based carbon cycle models to simulate carbon dynamics (Duanmu, 2016). Traditionally, field measurements are the most accurate methods for estimation. However, these approaches are usually time-consuming and labour intensive and cannot provide the continuous spatial distribution of biomass at large scales (Brown, 2002).In the present study, GIS was used as a complimentary tool and field measurement to obtain a map of the gardens in Ulhasnagar city, District Thane that would show the trees' location and give the researchers a clear picture of the green cover.

\section{MATERIALS AND METHODS}

\section{Study area}

In the city of Ulhasnagar, District Thane, Maharashtra, there are five Camps and collectively 51 gardens spread across the city. Only twelve gardens with a green cover were mapped using Geographical Information System (GIS).

\section{Methodology}

The GPS location of each tree in all the gardens was achieved with EpiCollect mobile app (worked with android phone/ HTC desire mobile phone) a web freeware application (www.epicollect.net). The application allows multiple surveyors to collect and submit data by smartphones, including GPS data and images, to an online database. The data was further displayed, analyzed, filtered and mapped using Google Maps, both on smartphones and PCs (Aanensen et al., 2009).

Above Ground Biomass (AGB) of trees was estimated using a non-destructive method on the basis of $D B H$ and tree height. The Diameter at Breast Height (DBH) was determined by measuring tree girth at breast height (GBH) approximately 1.3 meters above the ground, directly using a measuring tape ( Ravindranath and
Ostwald, 2008). The height of the tree was measured by the less expensive ocular method (Warran and Patwardhan,2009). Later AGB was calculated using the formula (Kulkarni et al., 2010) as follows:

AGB $(\mathrm{Kg})=$ Volume of tree $\left(\mathrm{m}^{3}\right) \times$ Wood density $\mathrm{Kg} / \mathrm{m}^{3}$ Arc view 10.2.1 software of GIS was used to project the above-ground biomass of gardens/parks in the study area of Ulhasnagar. Above-ground biomass values were entered in the software to create the GIS map that showed the exact location and value of aboveground biomass for each tree species in the study area. For preparing the maps IDW (Inverse Distance Weighted), an interpolation method was used (Shinde and Mahajan, 2015). Interpolation techniques are based on the principles of spatial autocorrelation, which assumes that objects close together are more similar than objects far apart. On the edges of the interpolated area, extrapolation is also reasonable.

\section{RESULTS AND DISCUSSION}

The present study using Arc GIS is one of the pioneering footsteps to understand the distribution of green cover in Ulhasnagar. Depending on the DBH values, the trees in the study area were categorized into six different diameter classes viz. Class I (6-12 inches), Class II (13-24 inches), Class III (25-36 inches), Class IV (37-48 inches), Class V (49-60 inches) and Class VI ( $>60$ inches) that indirectly corresponded with the age of the trees (Gharge and Menon, 2017a).In the present study, GIS-based map shows the location and value of above-ground biomass for each tree species found in the selected gardens. Ulhasnagar city (approx. 3336 acres), earlier the Sindhi migrant camp during the postindependence period, has five Camp regions and the gardens are in these camps. All the gardens vary in the area and the number of trees presents and are majorly maintained by the Ulhasnagar Municipal Corporation. In the study area, a totally of 15 gardens were mapped with the help of GIS; three bigger gardens Gol Maidan (2.5 acres with 493 trees) from Camp I, Sapna garden (1.25 acres with 215 trees) from Camp III and Prabhat garden (1.9 acres, with 171 trees) from Camp $V$ has been reported earlier by the authors (Gharge and Menon, 2017b).

The data in Table .1 represented the total number of trees and AGB $(\mathrm{Kg})$ mapped from all the twelve gardens in five camp regions of Ulhasnagar. Shivaji Udyan from Camp I, adjoining the famous Birla Mandir covered an area of 2.5 acres and had a total of only 286 trees. Around $80 \%$ trees were in DBH Class I \& Class II and appeared to be planted only in the last decade. The common trees were Delonix regia, Madhuca indica, Roystonia regia, Archentophoenix and Mimosops elengi, were common (Fig. 1).From Camp II, mapping of four gardens showed that Indira Gandhi Yadgar 
Table 1. Distribution of trees and total AGB $(\mathrm{Kg})$ in the gardens of Ulhasnagar, District Thane.

\begin{tabular}{lllll}
\hline S. No & Camp & Name of garden & Total trees & Total AGB (Kg) \\
\hline 1. & I & Shivaji Udyan & 286 & 111.914 \\
2. & II & Indira Gandhi Yadgar Udyan & 35 & 22.321 \\
3. & II & Premchand Pessumal garden & 15 & 8.277 \\
4. & II & UMC garden & 21 & 42.416 \\
5. & II & Nana Nani Udyan & 113 & 45.733 \\
6. & III & Pappu garden & 13 & 6.505 \\
7. & III & Boat Club & 67 & 248.363 \\
8. & III & Dasshera maidan & 303 & 156.713 \\
9. & IV & Swami Trilokdas Udyan & 36 & 119.875 \\
10. & IV & Shivaji ground & 15 & 21.933 \\
11. & IV & Jijamata Udyan & 06 & 21.922 \\
12. & V & Lal Saimata Garden & 72 & 10.456 \\
\hline
\end{tabular}

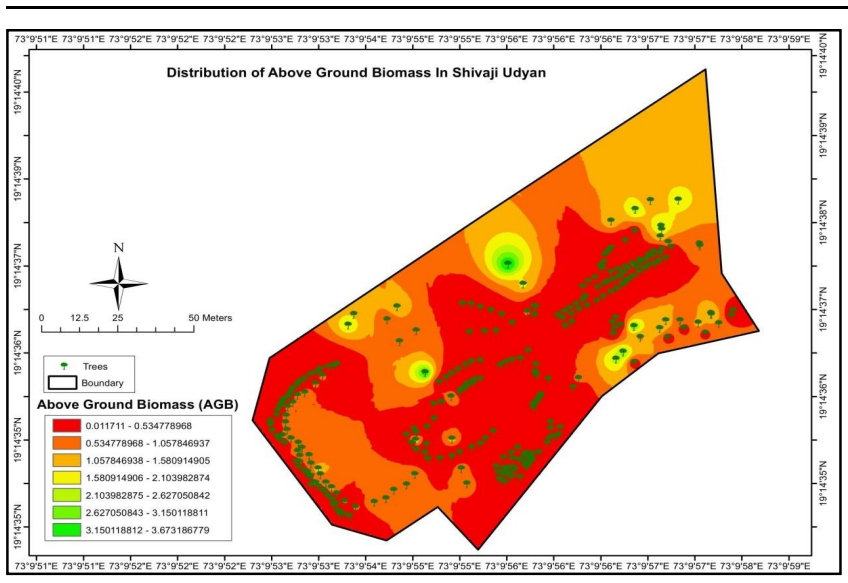

Fig.1. GIS map of Shivaji Udyan in Ulhasnagar.

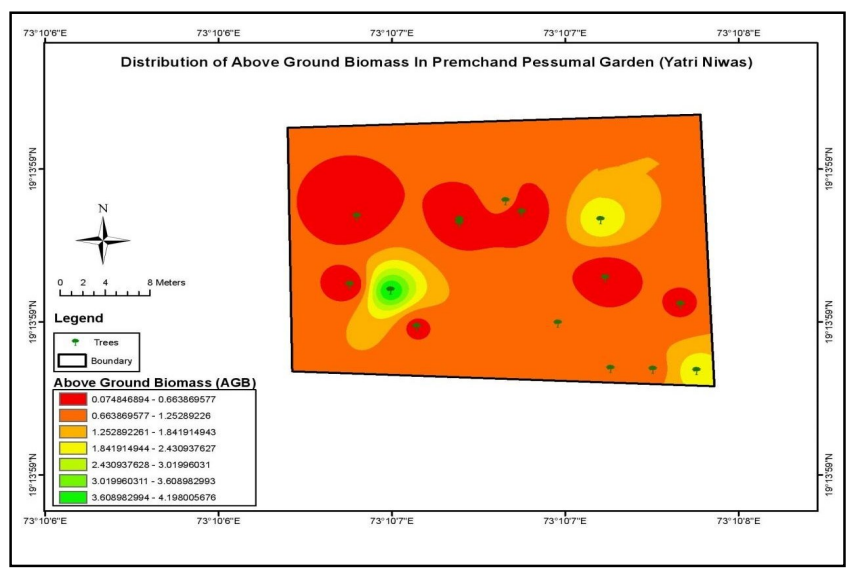

Fig. 3. GIS map of Premchand Pessumal garden in Ulhasnagar.

Udyan covered an area of 1.28 acres and with 35 trees. Polyalthia longifolia and Syzygium cumini had higher biomass indicating green colour on the GIS map (Fig. 2). Premchand Pessumal garden with an area of 0.63 acres and 15 trees showed a single Ficus religiosa tree in the diameter of DBH Class IV with higher biomass followed by Cocos nucifera and Ficus glomerata in Class III (Fig.3).UMC garden covers an area of 0.38

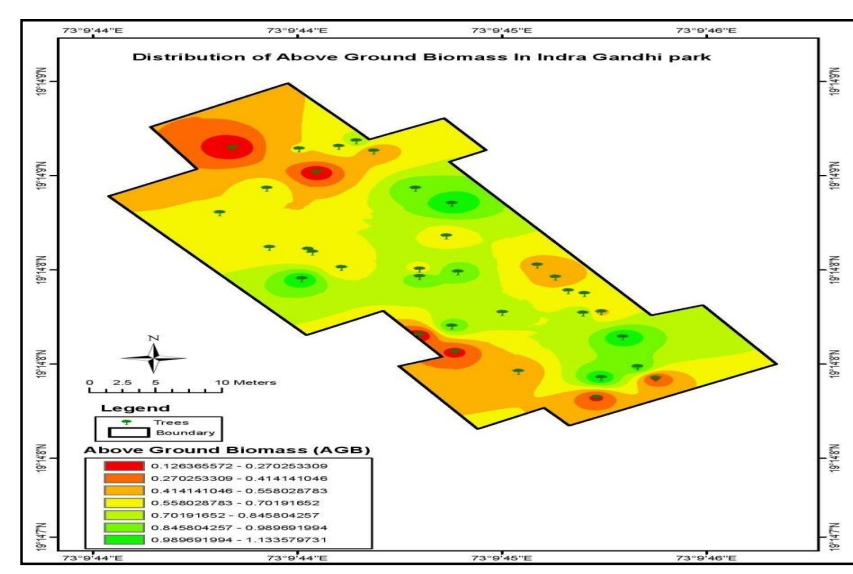

Fig. 2. GIS map of Indira Gandhi Park in Ulhasnagar.

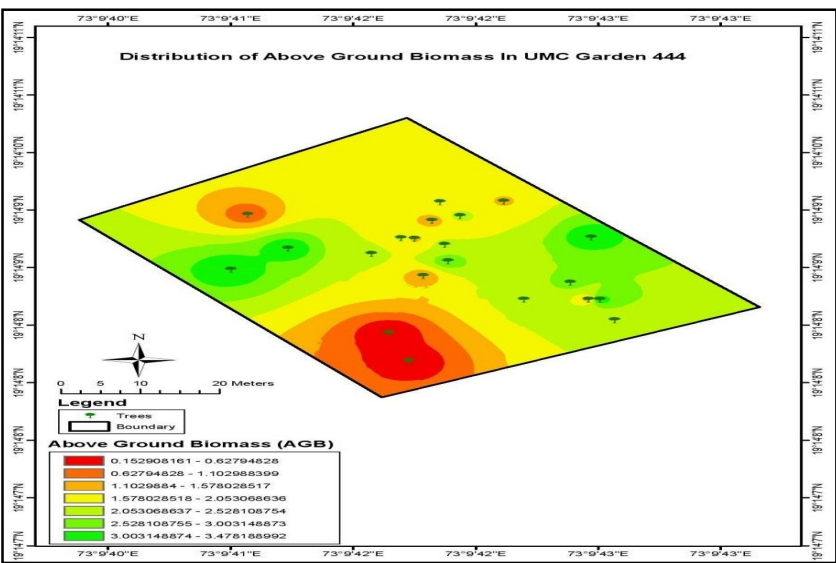

Fig. 4. GIS map of UMC Garden in Ulhasnagar.

acres and had only 21 trees. It appeared to be neglected due to the absence of trees in DBH Class I and II. All trees belonged to DBH Class III and IV and were at least 30 years old, dominated by Polyalthia and Samanea saman (Fig.4). Nana Nani Udyan admeasures an area of 0.249 acres and 113 trees. More than $85 \%$ of trees were young, belonging to Class I and II, few trees in Class III. Common trees with higher biomass were 
Syzygium cumini and Cassia fistula. Garden trees like Archentophoenix, Roystonia, and Polyalthia were common with lower diameter, therefore, with lower biomass (Fig.5).

Mapping three gardens from Camp III region ,Pappu garden established on $22^{\text {nd }}$ February, 2009, has an area of 0.19 acres and very few trees (13 trees). The majority of the trees were in DBH Class II (12 trees) and only one tree in Class III. The diameter of the trees corresponded well to the age of the trees. Higher biomass was represented by Samanea saman and Mangifera indica (Fig. 6 ). The Boat Club (area of 6.53 acres) present near Hira ghat was the largest garden in terms of area, but not well maintained with respect to green cover. A total of 67 trees were present here, and Peltophorum pterocarpum and Delonix regia (Class V) were with highest biomass showing green colour on the map. Trees like Delonix regia, Ficus religiosa, and $P$. pterocarpum were in Class IV showing average biomass indicating orange colour. The map clearly depicts that the garden consisted of a comparatively good number of trees with a larger diameter that contributed to the biomass (Fig.7). The area of Shrimati Indira Gandhi Udyan or Dasshera maidan is 1.79 acres with 303 trees. Despite the number of trees in multiple hundreds, the map shows an inclination to red colour than green

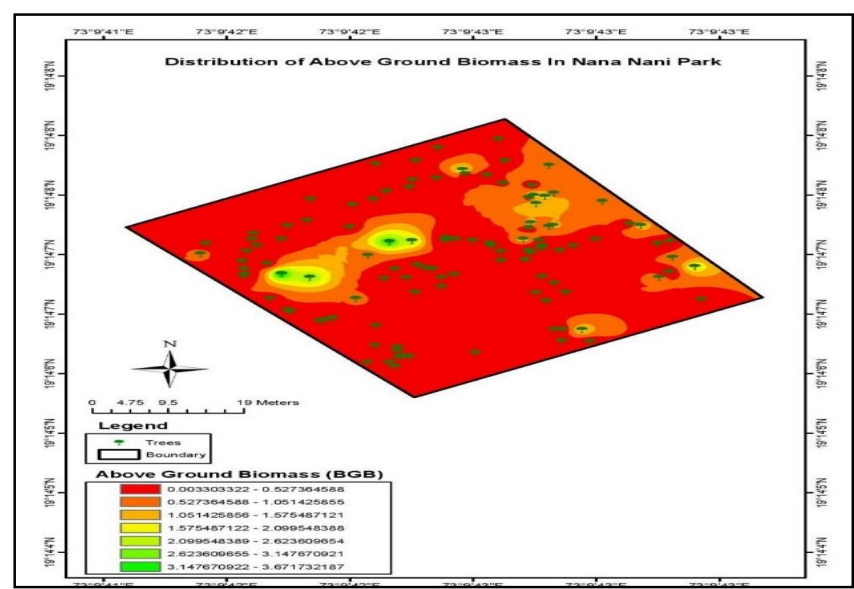

Fig. 5. GIS map of Nana Nani Park in Ulhasnagar.

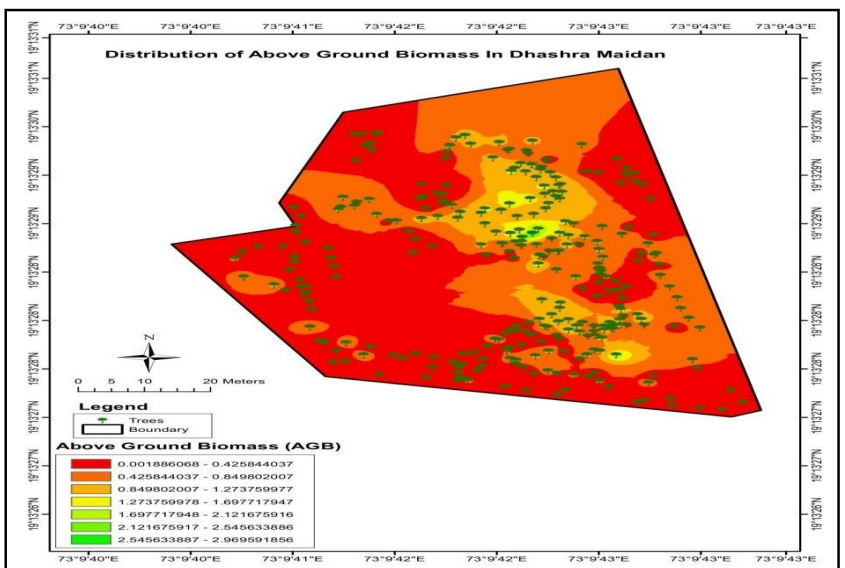

Fig. 7. GIS map of Dasshera maidan in Ulhasnagar. colour. This observation may be due to the fact that the trees present here were young with less biomass and belonging to DBH Class I (120) and Class II (155). Only few of them (28 trees) were in the diameter Class III (Fig.8).

Similarly, three gardens from the Camp IV region of Ulhasnagar were mapped. Swami Trilokdas Udyan established in 1984 with an area of 0.55 acres, had only 36 trees in the garden. More than $77 \%$ of the total trees were above 40 years old and few young trees.A large number of Samanea saman were present that showed high biomass indicating green colour, along with comparatively smaller trees like Mangifera indica, Roystonia regia, Grevillea robusta with lower biomass (Fig.9). Shivaji ground has an area of 0.322 acres with only 15 trees. All the trees belonged to DBH Class II and III except a single tree of Azadirchta indica (Class IV) having higher biomass (Fig. 10). Jijamata Udyan the smallest garden in the study area (0.065 acres), had only 6 trees. All trees were old, especially Samanea saman with large biomass of about $9.6751 \mathrm{Kgs}$ and diameter in the range of 60 inches and above, few other trees like Polyalthia and Cocos were present (Fig. 11 ). In Camp V, Lal Saimata Garden or Lala Lohi Udyan with an area of 0.738 acres had total 72 trees in the diameter Class I (60\%) and Class II (40\%) and indicat-

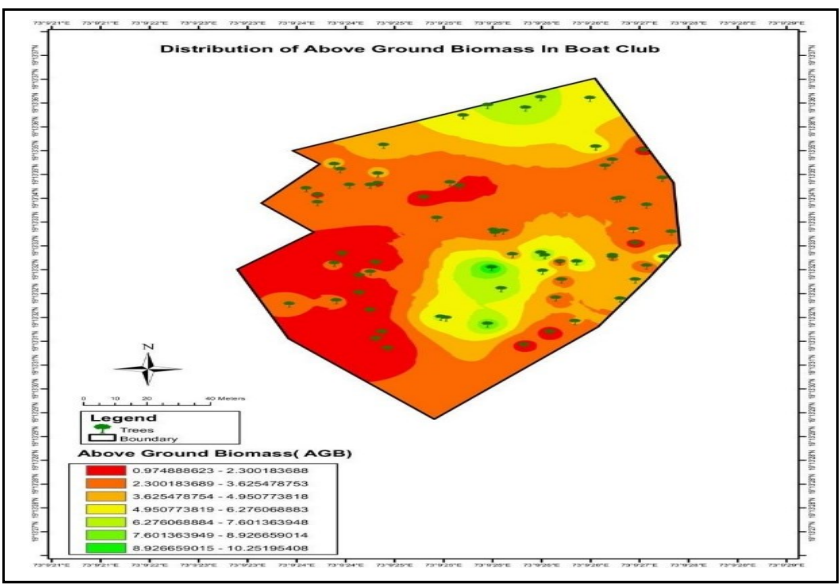

Fig. 6. GIS map of Boat Club in Ulhasnagar.

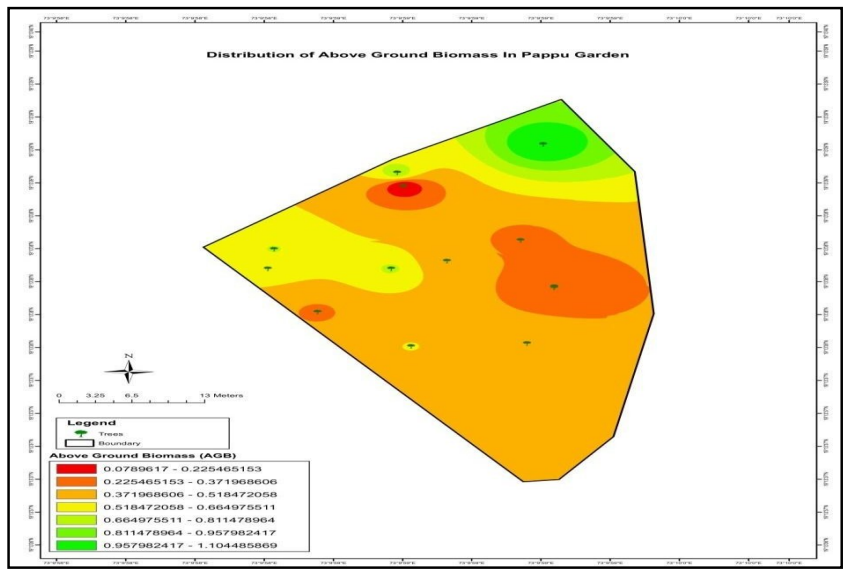

Fig. 8. GIS map of Pappu garden in Ulhasnagar. 
ed young trees in the area. Only Mangifera indica and Pongamia pinnata were trees with canopy that represented green colour in the map (Fig 12).

In the whole of Ulhasnagar, there are around 51gardens, though many gardens had poor green cover and could not be mapped due to the technical limitation encountered. A base map could be generated with the help of arc view only when a minimum of six trees were present at any location. The limitation projects the green cover status of this city. The GIS map would be an aid to visualize the situation of green distribution present today and envisage the situation for tomorrow. In all the GIS maps, the green dots reflected the specific location of the trees in the garden. The colour scheme used in the map actually correlated to the volume of biomass contributed by the green cover. Large canopy trees or trees with large diameters corresponded to the green colour. The trees with a canopy of the medium, especially Class III and IV size, were related to the yellow colour in the map. This feature was visible in Fig 1a, 1d, and 1h. The maps with the red colour indicated smaller canopy, new plantations or open grounds.

Several studies of urban green using GIS have been reported, like the Somjaichi Rai (Sacred grove) at

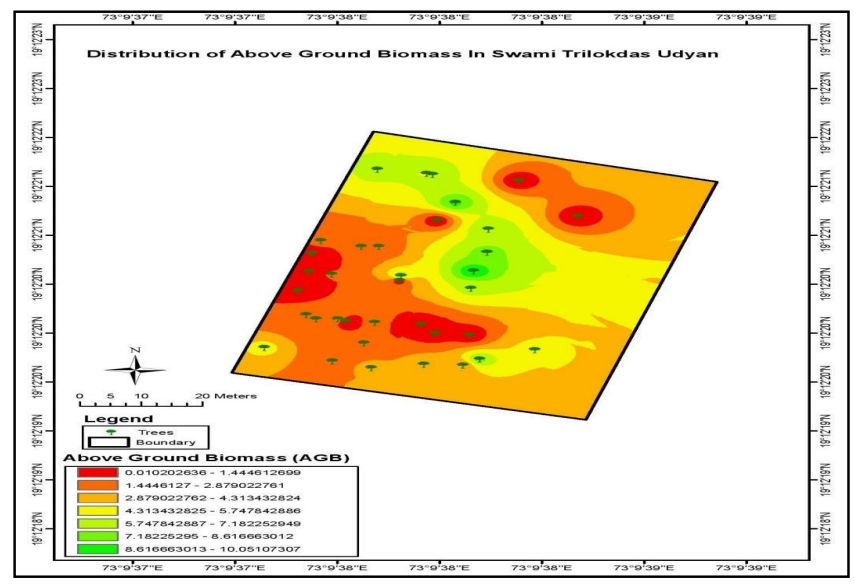

Fig. 9. GIS map of Swami Trilokdas garden in Ulhasnagar.

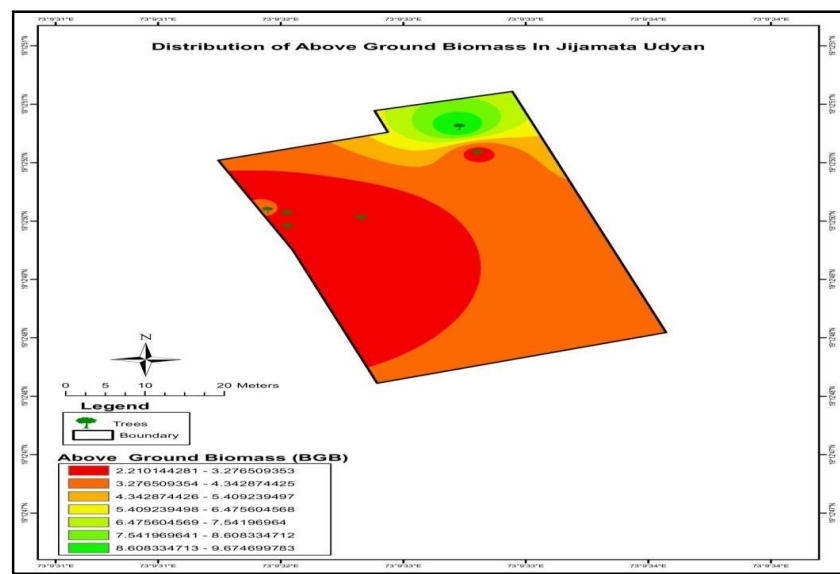

Fig. 11. GIS map of Jijamata Udyan in Ulhasnagar.
Nandghur village, in Bhor region (Hangarge et al., 2012), urban managed garden in the PimpriChinchwad City (Choudhari et al., 2014) and an academic institution (Mahajan et al.,2017) in the Pune region.GIS technology integrates common database operations such as spatial and non-spatial queries and spatial analysis with map's unique visualization and geographic benefits. These abilities distinguish GIS from other information systems and make it valuable to a wide range of public and private enterprises. GIS performs these tasks faster and with more sophistication than the traditional manual methods. Customized tools of GIS helped non-technical users to utilize functionalities of GIS without much technical expertise on that particular GIS software. Moreover, Green spaces are an important part of the urban ecosystem, contributing to human health, recreation, and survival. Urban green space management is subject to a complex assortment of interacting social, cultural, and economic factors, including governance, economics, social networks, multiple stakeholders, individual preferences, and social constraints (Yi-Wen et al., 2020). The most important challenge in this aspect is discovering the path to asses the balance of urban green spaces by better coupling the recreational activi-

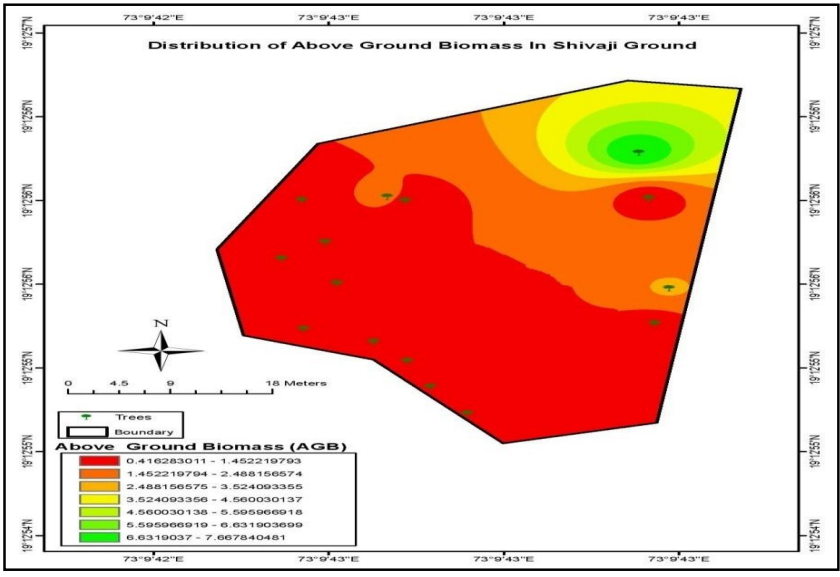

Fig. 10. GIS map of Shivaji Ground in Ulhasnagar.

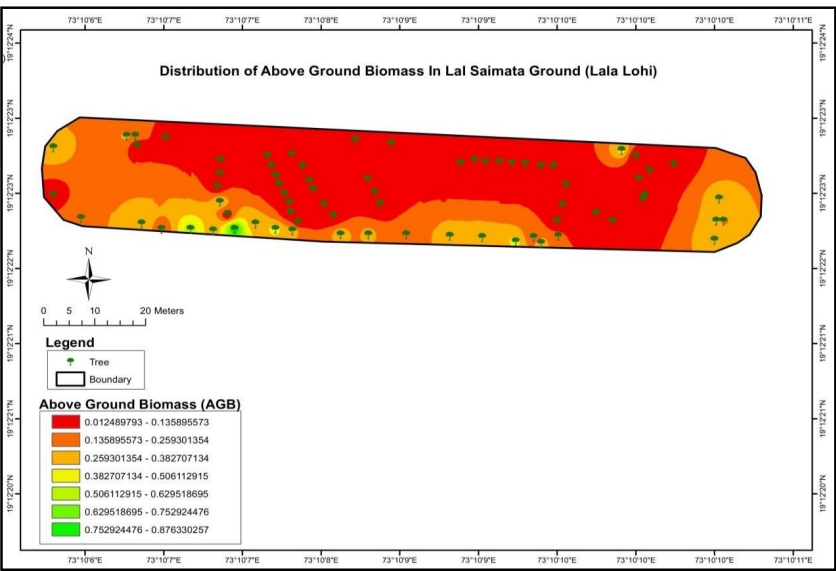

Fig. 12. GIS map of Lala Lohi Garden in Ulhasnagar. 
ties of urban residents and the function of urban green spaces.

\section{Conclusion}

The present study was an attempt to map the number of trees and assess the status of urban green spaces as gardens in Ulhasnagar, District Thane. The GIS map gives us the exact location of the actual tree in the map and, to some extent, do give a conclusive idea about the diameter Class or indirectly the age of the trees. These maps provide the researcher with an idea of the present situation of the gardens in terms of number of trees and their stage of growth as AGB in each garden under study. It also represents the current geographic data for analysis and has also helped the researcher to map the pattern of tree distribution in this urban environment. The land usage system prevailing in Ulhasnagar can be stated and introspected to achieve a more profitable approach to save the environment through the data generated. More profitable opportunities can be explored for tree planting initiatives within this urban environment. The resulting output can be quantitatively visualized and ecological benefits of trees can be experienced.

\section{ACKNOWLEDGEMENTS}

The authors thank all the staff from the Department of Botany, R.K. Talreja college; staff maintaining the gardens, Ulhasnagar Municipal Corporation for their support and staff of MS University, Baroda; for help in GIS mapping.

\section{Conflict of interest}

The authors declare that they have no conflict of interest.

\section{REFERENCES}

1. Aanensen D.M., Huntley D.M., Feil, E.J., al-Own F. \& Spratt B.G. (2009). Epi collect: Linking smartphones to web applications for epidemiology, ecology and community data collection. PLOS ONE, 4(9), e6968, DOI:10.137 1/ journal.pone.0006968.

2. Albro Sandra, L. (2020). Urban Greening with Sandra Albro. Sustainability Defined. Ep. 51, 08-21.

3. Brown,S. (2002).Measuring Carbon in forests: Current status and future challenges, Environ.Pollution,116,363372.DOI:10.1016/S0269-7491(01)00212-3

4. Choudhari, N.R., Mahajan, D.M., Gunale, V.R. \& Chas kar, M. G. (2014). Assessment of carbon sequestration potential of an urban managed garden in the PimpriChinchwad City, Environment Observer, 20, 63-67.

5. Duanmu, J. (2016). A multiscale based method for estimating coniferous forest above-ground biomass using low density airborne LiDAR data, Thesis, Lund University, Sweden.
6. Gharge S. \&Menon, G. (2017 a).Carbon sequestration potential of trees and soil in Swami Shantiprakash garden, Ulhasnagar, IJIRSET, 6 (7), 15075-15080,DOI:10.15680/ IJIRSET.2017.0607332.

7. Gharge S. \& Menon, G. (2017b). Assessment of carbon storage potential of trees and soil in the urban parks a step towards climate change mitigation, Int Journal of Current Research, 9(11), 61020-61025, DOI:10.24941/ IJCR.2017

8. Hangarge, L.M., Kulkarni, D.K., Gaikwad, V.B., Mahajan, D.M. \& Chaudhari, N., (2012). Carbon sequestration potential of tree species in Somjaichi Rai (Sacred grove) at Nandghur village in Bhor region of Pune District, Maharashtra State, India. Annals of Biological Research, 3(7), 3426-3429.

9. Jayasinghe, D.B.C., Hemakumara, G.P.T.S. \& Hewage, P. (2018). GIS-based assessment of the green space per capita in the City of Galle, Sri Lanka, Sri Lanka, Journal of Advanced Social Studies, 7 (2), 3-24.

10. Jennings, V., Larson, L. \& Yun, J. (2016). Advancing sustainability through urban green space: cultural ecosystem services, equity, and social determinants of health. Int. J. Environ. Res. Public Health, 13, 196 - 210. DOI:10.3390/ IJERPH13020196

11. Kulkarni, D. K., Nipunge, D.S.,Hangare,L.M. \& Kamble, P.B. (2010). Natural Heritage of forest conservation in Bhor region of Pune, India.Asian Journal of Environmental Science,5 (2), 94-98.

12. Le,Toans, T.,Quegan,S.,Davidson,M.W.J.,Balzter,H.,Paillo n, P., Papathanassiou, K., Plummer, S., Rocca, F., \& Shugart,H.(2011).The Biomass Mission: Mapping global forest biomass to better understand the terrestrial Carbon cycle, Remote Sense Environ.,115, 2850-2860, DOI:10.3 390/rs11111275.

13. Mahajan, D.M., Shinde V.R., \& Chasker M.G.,(2017). Assessment of biomass carbon pool of an academic institution in Pune, Maharashtra, SRJIS, 4, 4868-4877.

14. Qian, Y., Zhou, W., Yu W. \& Pickett, S.T.( 2015). Quantifying spatiotemporal pattern of urban green space: New insights from high resolution data. Landsc. Ecol., 30, 1165 -1173, DOI 10.1007/s10980-015-0195-3.

15. Ramaiah,M. \& Avtar, R. (2019). Rapidly Urbanizing India: A Review. Urban Sci., 3 (94), 1-16 DOI:10.3390/urbans ci3030094.

16. Ravindranath, N.H. \& Ostwald Madelene (2008). Carbon Inventory Methods, Handbook for Greenhouse Gas Inventory, Carbon Mitigation and Roundwood Production Projects, Springer-Verlang, p-304.

17. Shinde V.R.,\& Mahajan ,D.M. (2015). Carbon pool analysis of urban parks (Chh. Sambhaji Garden and Chittaranjan Vatika, Pune). Journal of Basic Sciences, 1(1), 20-27.

18. Warran, A. \& Patwardhan, A. (2009). Carbon sequestration potential of trees in and around Pune city. Research and Action In Natural Wealth Administration, Pune, India, C26/46,1-16.

19. Yi-Wen Ji, Lang Z., Jie Liu, Qicheng Z. \& Xinxin Z., (2020). Optimizing spatial distribution of urban green spaces by balancing sSupply and demand for ecosystem services. Journal of Chemistry, 1-10 DOI.org/10.11 $55 / 2020 / 8474636$. 